\title{
Матричные ИК фотоприемники на основе гетероструктур узкозонных полупроводников
}

\author{
М.В. Якушев, В.С. Варавин, В.В. Васильев, С.А. Дворецкий, В.Г. Ремесник, \\ И.В. Сабинина, Г.Ю. Сидоров, Ю.Г. Сидоров, А.В. Латышев \\ Институт физики полупроводников им. А.В.Ржсанова СО РАН, \\ Новосибирск, 630090, пр. Ак. Лаврентьева, 13
}

DOI 10.34077/RCSP2019-19

В настоящее время твердые растворы $\mathrm{Hg}_{1-\mathrm{x}} \mathrm{Cd}_{\mathrm{x}} \mathrm{Te}$ (кадмий-ртуть-теллур, КРТ) занимают лидирующее положение среди материалов, на основе которых разрабатываются инфракрасные фотоэлектрические детекторы излучения. Благодаря тому, что $\mathrm{HgTe}$ обладает инвертированной зонной структурой или, иначе, «отрицательной» шириной запрещенной зоны, в твердом растворе $\mathrm{Hg}_{1-\mathrm{x}} \mathrm{Cd}_{\mathrm{x}} \mathrm{Te}$ можно получить произвольную ширину запрещенной зоны от 0 до 1.6 эВ и настроить детектор на выбранное окно прозрачности атмосферы.

Использование подложек из CdZnTe позволяет выращивать эпитаксиальные структуры $\mathrm{CdHgTe} \mathrm{c}$ низкой плотностью прорастающих дислокаций. Однако, несмотря на затраченные гигантские усилия и средства, подложки большой площади из CdZnTe остаются дорогим и эксклюзивным изделием с невоспроизводимыми характеристиками. В связи с этим повсеместно разрабатываются технологии создания гетероструктур $\mathrm{CdHgTe}$ на альтернативных подложках, таких как $\mathrm{Si}, \mathrm{GaAs}, \mathrm{Ge}$. Использование подложек из кремния позволяет получать матричные фоточувствительные элементы, согласованные по коэффициенту термического расширения с кремниевой интегральной микросхемой считывания сигнала (мультиплексором).

Большое различие параметров кристаллических решеток, химическая и структурная несогласованность КРТ на $\mathrm{Si}$ делает задачу разработки и изготовления ИК ФП на основе гетероструктур КРТ/Si, с параметрами, не уступающими параметрам ИК ФП на основе структур КРТ на согласованных подложках CdZnTe, чрезвычайно сложной.

В ИФП СО РАН разработано и изготовлено уникальное российское оборудование для выращивания КРТ методом МЛЭ. Проведены комплексные исследования всех этапов выращивания гетероэпитаксиальных структур $\mathrm{CdTe}$ и $\mathrm{CdHgTe}$ на подложках из арсенида галлия и кремния ориентацией (013) диаметром до 100 мм. Подложки, ориентированные по плоскости (013) выбраны нами, так как они позволяют выращивать слои КРТ с высокими параметрами в более широком диапазоне условий роста по сравнению с наиболее часто используемыми подложками (211). Исследованы механизмы формирования гетеропереходов $\mathrm{A}^{\mathrm{II}} \mathrm{B}^{\mathrm{VI}} / \mathrm{GaAs}$ и $\mathrm{A}^{\mathrm{II}} \mathrm{B}^{\mathrm{VI}} / \mathrm{Si}$ и кинетика роста слоев CdZnTe и CdHgTe на высокоиндексных поверхностях. В результате разработана технология, позволяющая создавать на альтернативных подложках нелегированные и легированные In пленки $\mathrm{CdHgTe} \mathrm{c} \mathrm{низкой} \mathrm{плотностью} \mathrm{морфологических} \mathrm{и} \mathrm{структурных} \mathrm{дефектов.}$

Установлено, что в пленках МЛЭ КРТ/Si вне зависимости от состава наблюдаются магнетополевые зависимости проводимости и коэффициента Холла в диапазоне магнитных полей $0,05 \div 1$ Тл при $77 \mathrm{~K}$. Эти зависимости хорошо описываются с привлечением двух типов электронов: с высокой и с низкой подвижностью, различающимися на порядок величины.

Установлено, что в гетероструктурах $\mathrm{KPT} / \mathrm{Si}(013)$ доминирующим генерационнорекомбинационными уровнями являются уровни, связанные с вакансиями в подрешетке металла. Заполнение вакансий приводит к снижению вклада рекомбинации Шокли-Рида и к возрастанию времени жизни неосновных носителей заряда в несколько раз до величин ограниченных фундаментальными межзонными механизмами рекомбинации.

На полученных структурах изготовлены матричные фотоприемники различного формата на диапазоны длин волн 1-3, 3-5 и 8-14 мкм, работающие как при 77К, так и повышенных температурах, с параметрами не уступающими зарубежным аналогам. Впервые изготовлен фотоприемник формата $2000 \times 2000$ элементов для средневолнового спектрального диапазона. 